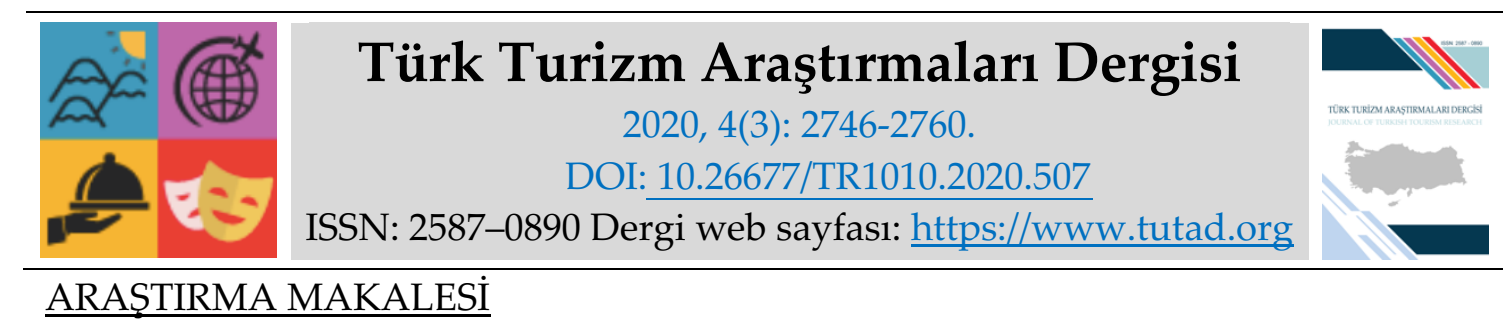

\title{
Sanal Gerçeklik ve Artırılmış Gerçeklik Uygulamalarının Rekreatif Faaliyetlere Yansıması: Dijital Rekreasyon
}

Dr. Öğr. Üyesi F. Kübra AYLAN, Selçuk Üniversitesi, Turizm Fakültesi, Konya, e-posta: kubraceliloglu@gmail.com ORCID: https://orcid.org/0000-0002-6703-2934

Dr. Öğr. Üyesi Serkan AYLAN, Selçuk Üniversitesi, Turizm Fakültesi, Konya, e-posta: serkaylan@gmail.com

ORCID: https://orcid.org/0000-0002-7262-4440

Öz

Son yıllarda internetin ve teknolojinin hızla gelişmesi ile birlikte ortaya çıkan sanal ve artırılmış gerçeklik kavramları, birçok alanda olduğu gibi turizm ve rekreasyon sektöründe de kullanılmaya başlayarak dönüşüme yol açmıştır. Bu bağlamda çalışmanın amacı, sanal gerçeklik ve artırılmış gerçeklik alt yapısı sayesinde ortaya çıkan dijital rekreasyon kavramının kapsamını belirlemek ve dijital rekreasyon faaliyetlerini sınıflandırmaktır. $\mathrm{Bu}$ amaç doğrultusunda çalışmada, dijital rekreasyon kavramı, dijital rekreatif faaliyetlerinin uygulama örnekleri araştıılmış olup, elde edilen veriler neticesinde dijital rekreasyon faaliyetleri sınıflandırılmıştır. Araştırma nitel araştırma yöntemiyle desenlenmiş olup, ikincil verilerden yararlanılmıştır. Araştırmanın bulgularına göre, dijital rekreasyon kavramı; sanal gerçeklik tabanlı dijital rekreasyon ve artırılmış gerçeklik tabanlı dijital rekreasyon olmak üzere iki temaya ve alt kategorilere ayrılmıştır. Çalışmada, sanal gerçeklik tabanlı dijital rekreasyon faaliyetlerinin sırasıyla en fazla sportif, kültürel ve doğaya yönelik alanlarda, artırılmış gerçeklik tabanlı dijital rekreasyon faaliyetlerinin ise, sportif, kültürel ve sanatsal alanlarda ortaya çıktı̆̆ tespit edilmiştir.

Anahtar Kelimeler: Dijital Rekreasyon, Dijital Rekreatif Faaliyetler, Sanal Gerçeklik, Artırılmış Gerçeklik.

Makale Gönderme Tarihi: 31.04 .2020

Makale Kabul Tarihi: 02.07.2020

Önerilen Atıf:

Aylan, F. K. ve Aylan, S. (2020). Sanal Gerçeklik ve Artırılmış Gerçeklik Uygulamalarının Rekreatif Faaliyetlere Yansıması: Dijital Rekreasyon, Türk Turizm Araştırmaları Dergisi, 4(3): 2746-2760.

(C) 2020 Türk Turizm Araştırmaları Dergisi. 


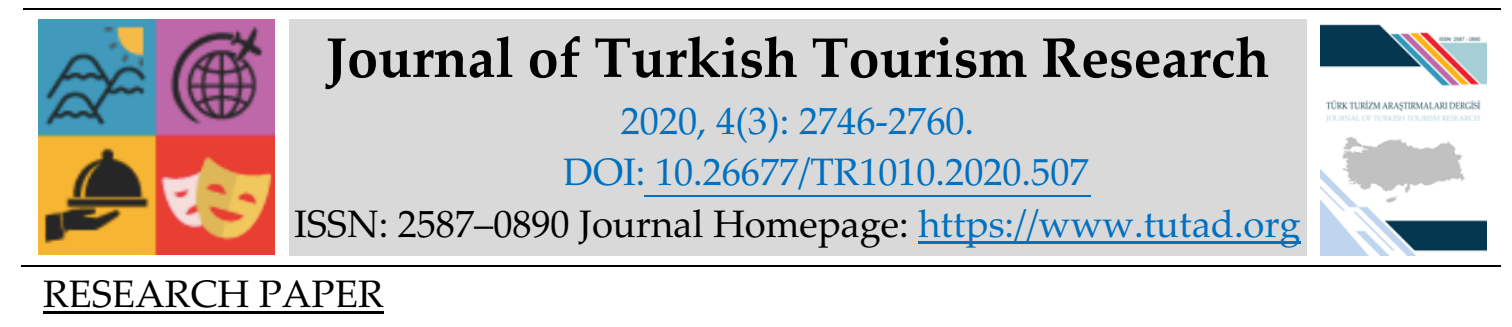

\title{
Reflection of Virtual Reality and Augmented Reality Applications to Recreational Activities: Digital Recreation
}

Assistant Prof. Dr. F. Kübra AYLAN, Selçuk University, Faculty of Tourism, Konya, e-mail: kubraceliloglu@gmail.com

ORCID: https://orcid.org/0000-0002-6703-2934

Assistant Prof. Dr. Serkan AYLAN, Selçuk University, Faculty of Tourism, Konya, e-mail: serkaylan@gmail.com

ORCID: https://orcid.org/0000-0002-7262-4440

\begin{abstract}
In recent years, the concepts of virtual and augmented reality, which have emerged with the rapid development of internet and technology, have started to be used in the tourism and recreation sector as well as in many other fields. Virtual reality and augmented reality practices led to change and transformation in tourism and recreation activities. In this context, the aim of the study is to determine the scope of the digital recreation concept that arises thanks to the virtual reality and augmented reality infrastructure and to classify the digital recreation activities. In line with this purpose, the concept of digital recreation, application examples of digital recreational activities were researched and digital recreation activities were classified as a result of the obtained data. The research was designed with qualitative research method and secondary data were used. According to the findings of the research, the concept of digital recreation; It is divided into two themes and sub-categories: virtual reality based digital recreation and augmented reality based digital recreation. In the study, it was determined that virtual reality-based digital recreation activities occur mostly in sportive, cultural and natureoriented areas, and augmented reality-based digital recreation activities occur in sportive, cultural and artistic areas respectively.
\end{abstract}

Keywords: Digital Recreation, Digital Recreative Activities, Virtual Reality, Augmented Reality. Received: 31.04 .2020

Accepted: 02.07.2020

Suggested Citation:

Aylan, F. K. and Aylan, S. (2020). Reflection of Virtual Reality and Augmented Reality Applications to Recreational Activities: Digital Recreation, Journal of Turkish Tourism Research, 4(3): 2746-2760.

(C) 2020 Türk Turizm Araştırmaları Dergisi. 


\section{Gíriş}

Günümüzde internetin gelişimi sayesinde, dünya üzerindeki bilgi akışı ve toplumlar arasındaki etkileşim artmıştır. Bununla birlikte bilgi iletişim teknolojileri, insanların yaşam şekillerini ve hayata bakış açılarını değiştiren en önemli buluşlardan biridir. Bilgi iletişim teknolojileri sayesinde dünya üzerinde sınırlar ortadan kalkmış, tüketici istek ve beklentilerinde önemli değişimler meydana gelmiştir. Günümüzde robotlaşma, nesnelerin interneti, yapay zeka, sensörler, bilişsel teknolojiler, nanoteknoloji, internet hizmetleri, kuantum bilişim, giyilebilir teknolojiler, arttırılmış gerçeklik, akıllı sinyalizasyon, akıllı robotlar, büyük veri, 3D ve akıllı şebekeler gibi yeni nesil teknolojiler hayatın bir parçası olmuştur (Bahar vd., 2019:72). Teknolojideki ilerlemelerin, birçok şekliyle, turizm üzerinde doğrudan ve kalıcı etkileri vardır. Son zamanlarda, bilgi ve iletişim teknolojilerindeki (BİT) gelişmeler, turizmi önemli ölçüde dönüştürmekte, tüketici tercih ve talebinden, saha yönetimine kadar çeşitli alanlarda etkileri olmaktadır (Guttentag, 2010:637).

İnsanların, teknolojik gelişmelere uyum sağlaması, sevmesi ve merak etmesi ile birlikte, turizm ve rekreatif faaliyetlerin gerçekleşme biçiminde önemli değişimler meydana gelmiştir. Örneğin, birçok turistin interneti seyahat bilgisi aramanın bir aracı olarak benimsemiş olması sayısız turizm işletmesi ve kuruluşu kendilerini çevrimiçi olarak sanal dünyaya entegre etmek zorunda bırakmıştır. Buradan yola çıarak turizm işletmeleri gelişen teknolojiye adapte olmaları sonucunda, müşterilerin farklı deneyimler yaşamasına imkân sağlamakta, işlerin yürütülme sürecinde zaman tasarrufu elde etmekte, verilen hizmetin kalitesi arttırılmakta ve işletme maliyetleri düşürülmektedir. Yine destinasyonlara daha fazla turist çekmek amacıyla yapılan tanıtım faaliyetlerinde, $360^{\circ}$ panoramik geziler gibi teknolojik gelişmelerden faydalanılmaktadır.

Teknolojide yaşanan gelişmeler, birçok sektörü etkilemesinin yanı sıra, fiziksel gerçekliğe bir alternatif olan bambaşka dijital bir boyutun ortaya çıkmasına sebep olmuştur. Bryce (2018) çalışmasında belirttiği gibi, bilgi iletişim teknolojileri ve internet, boş zaman etkinliklerine katılmak için yeni alanlar oluşturarak, boş zaman kavramlarını ve organizasyonunu değiştirebilecek, çağdaş boş zaman aktivitesi için önemli alanlar olarak ortaya çıkmaktadır. Teknolojik cihazlarla yapılan boş zaman etkinlikleri, geleneksel boş zaman faaliyetlerinin aynı işlevlerini yerine getirmektedir (Mokhtarian vd., 2006:263). Özellikle sanal gerçeklik uygulamaları sayesinde insanlar, gerçekleştirmek istenen birçok rekreatif faaliyeti dijital ortamda yapabilmektedir. Sanal gerçeklik uygulamaları bir rekreatif faaliyetin tamamen dijital bir ortamda yapılmasına olanak sağlarken, artırılmış gerçeklik uygulamaları gerçek ve sanal ortamı bir araya getirerek dijital rekreatif faaliyetlerin gerçekleştirilmesine olanak sağlamıştır. $\mathrm{Bu}$ bağlamda çalışmada, dijital rekreasyon kavramı tanımlanmış ve dijital rekreasyon uygulamaları incelenerek, sınıflandırılması yapılmıştır.

\section{KAVRAMSAL ÇERÇEVE}

\section{Sanal Gerçeklik}

Sanal gerçeklik; masaüstü veya dizüstü bilgisayarlar, bir kabin ortamı veya başa takılı görüntüleyiciler gibi farklı görüntüleme donanımlarıyla kullanıcılara belirli bir ortamda bulunma hissi veren üç boyutlu benzetim ortamlarıdır (Kaleci vd., 2017:670). Sanal gerçeklik, günümüzde eğitim başta olmak üzere, eğlence, otomotiv, mimari, tıp gibi çeşitli alanlarda kullanılmaya başlanmıştır. Sanal gerçeklik aracı olan sanal gerçeklik gözlükleri, bulunulan sanal ortamın kişiler üzerinde gerçek dünyada yaşandığı hissi yaratır. Sanal deneyim sonucu oluşan tatmin hissinin kişilerde yarattığı etkinin arttırılması planlanır. 
Sanal gerçeklik uygulamalarında, stereo kulaklık ve gözlükten oluşan bir başlık ve hareketleri algılayabilen özel eldiven veya giysiler kullanılmaktadır. Bu özel giysilerle birlikte uygun bilgisayar donanımına bağlanarak 3B olarak sanal dünyada geziler yapılabilir. Örneğin, sanal gerçekliğe uyarlanmış bir müzeyi sanki gerçekten müzedeymiş gibi koltukta oturarak gezebilir, şehir veya müze turu yapabilir, sanal bir kafede yine sanal insanlarla tanışıp sohbet edilebilmektedir. Ayrıca günümüzde sanal gerçekliği kullanan birçok oyun üretilmiştir ve yaygın olarak kullanılmaktadır (Ekinci ve Özer, 2019: 148; Yılmazel, 2013: 67).

Sanal gerçeklik uygulamalarının, tüketicilere sanal deneyim yaşatmalarının yanı sıra, satın alma süreçlerinin bilgi arama ve alternatiflerin değerlendirilmesi aşamalarında da kolaylık sağlayacağı düşünülmektedir. Örnek vermek gerekirse, tatil yapılacak otelin seçiminde eldeki dışsal bilgi kaynakları tüketici yorumları, işletmenin kendi çektiği fotoğraflar, tur şirketinin bilgilendirmesi ile sınırlıyken sanal gerçeklik teknolojisi sayesinde otelin içini geziyormuş hissi veren bir bilgi türü tüketicinin bilgileri değerlendirme ve ikna olması sürecinde tek plan fotoğraftan daha etkin olacaktır. Bu bağlamda sanal gerçeklik gözlüklerinin bu teknolojiye ikâme dışsal bilgi türlerine göre daha etkin, etkileşimli, tüketiciyi daha kolay ikna edecek bir dışsal bilgi türü olduğu düşünülmektedir. Sanal gerçekliğin özelliklerini dört maddede toplayabiliriz (Yolcu vd., 2017:4-5):

1) Üç boyutlu sanal ortamlar yaratmak.

2) Çoklu duyusal (multisensory) kanallarla gerçek zamanlı kullanıcı etkileşimi

3) Kullanıcıların kendilerini sanal ortamın içindeymiş gibi hissetmesi (immersion)

4) Gerçek zamanda doğal manipülasyon aracılığıyla sezgisel etkileşim (intuitive interaction).

Turistik ürün pazarlamasında görsellikten faydalanan seyahat acenteleri, otel işletmeleri, tur operatörleri, yerel turizm yönetimleri ve birçok turizm paydaşları pazarlama ve tutundurma faaliyetlerinde $360^{\circ}$ sanal gerçeklik imkânlarından faydalanmaları etkili bir yöntem olacaktır. Sanal gerçeklik ve arttırılmış gerçeklik gibi ileri teknolojiler geleneksel pazarlama faaliyetlerini geride bırakarak kullanıcıları iki boyutun sıkıcılı̆̆ından kurtararak onları üç boyutlu daha gerçek ve daha çok duygu ile hissedilebilecek ortamların oluşturulması, talebi artıracağı düşünülmektedir (Öngider ve Yazıcı, 2020: 133). Aynı zamanda turizmde her türlü pazarlamanın ve rezervasyonların sanal ortamda yapılması da internetin çok yaygın kullanıldığı dünyamızda turizmin avantajlarından biridir. İnsanların evlerinden çıkmadan, sanal gerçeklik uygulaması ile gitmek istedikleri otelleri gezip, odalarını önceden 3 boyutlu görerek seçmeleri, insanların gözünde diğer otellere göre o otel için daha olumlu imaj yaratılmasına neden olacaktır. Otel personeli içinde sanal gerçeklik uygulaması, motive edici olabilecektir. Çalışan personelin yanında otelin her alanındaki misafirleri 3 boyutlu gösteren bir cihazın olması personelin işini kolaylaştırabilecektir (Arat ve Baltacıoğlu, 2016:110).

\section{Artırılmış Gerçeklik}

Teknoloji temelli ve birbirine benzer kavramlar olarak görülen sanal gerçeklik ile artırılmış gerçekliğin farkı şu şekilde ortaya konmaktadır; sanal gerçeklik, bilgisayar kaynaklı üç boyutlu oyunlarda karşılaşılan, kullanıcının bu ortama girdiğinde dünya ile ilişkisinin tamamen yok olduğu bir ortam olarak ifade edilebilir. Buna karşın artıılmış gerçeklik; gerçek dünya ile bağlantısını devam ettiren, veri ve görüntülerin gerçek dünya görüntülerine eklenebildiği, gerçek ve sanal nesnelerin aynı ortamda birlikte algılanmasını sağlayan bir ortam olarak ifade edilebilir (İçten ve Bal, 2017: 111). Artırılmış gerçeklik (augmented reality), dijital materyalleri 
gerçek dünya nesnelerine yansıtan teknolojileri ifade eder (Bingöl, 2018:46). Artırılmış gerçeklik, gerçek ve sanalı birleştirerek, gerçek zamanlı etkileşim ve üç boyutlu görüntüleme imkânı sağlayan teknolojik sistemlerdir (Azuma, 1997:355; Altınpulluk ve Kesim, 2015).

Artırılmış gerçeklik, dijital içeriğin sorunsuz bir şekilde gerçek dünya üzerine kaplanmasını ve gerçek dünya algılarının karışmasını sağlamaktadır. Artırılmış gerçeklik ile birlikte, pek çok kişinin beklediği 2 boyutlu ve 3 boyutlu nesnelerin yanı sıra, ses ve video dosyaları, metinsel bilgiler ve hatta koku veya dokunsal bilgiler gibi dijital varlıklar, kullanıcıların gerçek dünya algilarına dâhil edilebilmektedir. Dâhil edilen bu bilgiler bireylerin çevresinde neler olup bittiğini anlamalarına yardımcı olmak ve geliştirmek için hizmet edebilir. Artırılmış gerçekliğin doğasında bulunan dijital işaretlemeler, kullanıcıların gerçek dünyayı "eklenen" verilerle birlikte tek bir kesintisiz ortam olarak algılamalarını sağlamaktadır (Cankül, Doğan ve Sönmez, 2018: 580). Gerçeklik uygulaması, kullanılan teknolojiler dikkate alındığında, optik temelli teknolojiler ve video temelli teknolojiler olarak iki grupta değerlendirilmektedir. Bu iki teknoloji arasındaki temel farklılık gerçek ve sanal dünyanın bütünleştirilmesiyle oluşan sahnenin görüldüğü yerdir. Optik sistemlerde bütünleştirilmiş sahne gözlük aracılığıyla gerçek dünyada görülürken, video temelli sistemlerde bütünleştirilmiş sahne bilgisayar/tablet/mobil cihaz üzerinde görülmektedir (Somyürek, 2014:68).

Bilinen ilk artırılmış gerçeklik uygulaması olan Virtural Fixtures, 1992 yılında Louis Rosenberg tarafından Amerikan Hava Kuvvetleri bünyesinde geliştirilmiştir (Kamacıoğlu, 2018:22). İlk başlarda askeri endüstri, sanayi ve tıp alanlarında kullanılan (Caudell ve Mizell, 1992; Cover, vd., 1993), artırılmış gerçeklik; mimarlık, mühendislik ve inşaat endüstrisine araştırma aşamasında görselleştirme yoluyla önemli avantajlar sağlayacak ileri bilgisayar teknolojilerinden biridir. Artırılmış gerçeklik sadece endüstri ile sınırlı kalmayıp; sağlık, eğitim, havacilık, savunma, reklam, pazarlama, yayıncllı, seyahat, emlak, otomotiv, müzecilik, eğlence ve dijital oyun gibi alanlarda teknolojideki değişime paralel olarak kullanılmaktadır (Bingöl, 2018:48).

Yenilikçi bir teknoloji olarak artırılmış gerçeklik, müzeler/sergiler ve açık hava maceraları gibi birçok turizm ortamında eşsiz deneyimler oluşturmaya başlamıştır (Demirezen, 2019: 8-9). Artırılmış gerçeklik teknolojisinin gelişimi, yeni yazılım ve uygulamalar oluşturularak devam etmektedir. Bireylerin günlük hayatını bir bakıma kolaylaştıracak olan artırılmış gerçeklik teknolojilerinin çok yakın bir gelecekte özellikle akıllı telefonlarda yoğunlukla kullanılacağı öngörülmektedir. İlerde artırılmış gerçeklik teknolojileri sayesinde; gezilen şehirde görülen herhangi bir müze ya da binaya ait bilgilere anlık erişim sağlanabilecek, otellerde boş oda olup olmadığı ve oda fiyatları bilgileri hatta bir metronun nereye gittiği bile kolaylıkla görülebilecektir. Bunun için bireyin akıllı telefonunu bilgi edinmek istediği nesneye doğrultması yeterli olacaktır (Özgüneş ve Bozak, 2017:149).

\section{Dijital Rekreasyon}

Sanal gerçeklik ve artırılmış gerçeklik teknolojilerinin gelişmesi birçok alanda olduğu gibi, birer boş zaman değerlendirme faaliyetleri olan turizm ve rekreasyon aktivitelerinde de kendine yer bulmuştur. "Sanal gerçeklik, toplumun boş zamanların, içinde bulunduğu rekreasyon faaliyetlerini ve seyahatlerini nasıl kullandığına dair devrim yaratma potansiyeline sahiptir. Mevcut boş zaman olanakları seçeneklerimizi yeniden tanımlayacak ve gerçek ya da hayali bir yere seyahat etmeyi sağlayacaktır" (Hobson ve Williams, 1997: 34). Günümüzden yirmi üç yıl öncesinde yazılan bu cümlelerin, bugünlerde gerçekleştiği görülmektedir. Hjalager (2015)'e göre artırılmış gerçeklik, 
turizmi değiştiren yeniliklerden biridir ve artırılmış gerçeklik hızlı bir şekilde turizm gezileri, müze ve etkinliklerde gerçekleştirilen canlandırmalar için önemli bir araçtır.

Turizmin doğası gereği içerisinde yer değiştirme, ikâmet edilen şehrin dışına seyahat etme ve harcama yapma gibi unsurlar mevcut iken, rekreasyonda ise yaşanılan yerin dışına herhangi bir seyahat etme ve ücret ödeme zorunluluğu yoktur. Dolasıyla insanlar evlerinin içinde veya bahçelerinde dahi rekreatif faaliyette bulunabilmektedirler. Bu açılardan bakıldığında insanlar, kendi evleri içinde veya gittikleri turistik destinasyonlarda, başta bilgisayarlar olmak üzere, 3D sanal gözlükler, akıllı cep telefonları vb. teknolojik cihazlar sayesinde sanal turlar veya artırılmış gerçeklik destekli geziler yapabilmektedir. Bu aşamada karşımıza sanal turizm ve sanal rekreasyon çıkmaktadır. Sanal turizm, Kozak ve Özkeroğlu (2018: 404) tarafından şu şekilde tanımlanmıştır; "İnsanların belli bir süreliğine bulundukları gerçek ortamlardan zihinsel olarak uzaklaşarak "yok mekânlara" bir ekonomik bedel ödeyerek gerçekleştirdikleri sanal ziyaretler ve ilgili faaliyetlerin tümüdür. Yine ayn yazarlara göre sanal rekreasyon ise, "Zaman ve mekân bağımlılı̆̆ olmadan, insanda gerçekmiş hissi yaratarak olağanüstü deneyimler sunan, gönüllü ve ücret ödeme zorunluluğu olmadan da gerçekleşebilen deneyimlerin tümüdür" şeklinde tanımlanmıştır (Kozak ve Özkeroğlu, 2018: 405). Bu tanımlardan da anlaşılacağı üzere, sanal turlar ve sanal rekreasyon arasındaki fark olarak "ücret ödeme zorunluluğu" yani turizmde olup da rekreasyonda zorunlu olmayan ekonomik harcama yapma zorunluluğu bulunmaktadır. Bu aşamada şöyle bir soruyla karşılaşılmaktadır, "ücretsiz sanal tur yapan bireyler hangi kategoriye konulacaktır?" Bu sorunun cevabı olarak aslında sanal turları ve sanal rekreasyon kavramını da içine alan dijital rekreasyon kavramı kullanılabilir. Dijital kelimesinin Türk Dil Kurumu sözlügüüde 3 anlamı içerdiği görülmektedir. Bunlar (TDK, 2020);

1.sifat: Sayısal,

2. sıfat: Verileri bir ekran üzerinde elektronik olarak gösteren,

3. isim: Fizik verilerin bir ekran üzerinde elektronik olarak gösterilmesidir.

Kozak ve Özkeroğlu (2018) çalışmalarında, sanal turizm uygulaması olarak açıklanan kavramın "sanal rekreasyon" veya "dijital rekreasyon" kapsamında ele alınmasında fayda olduğunu belirtmiştir. Bu noktada dijital rekreasyon için şu şekilde bir tanımlama yapılabilir; "İnsanların boş zamanlarını değerlendirmek, dinlenmek, bedenen ve zihnen yenilenmek, kaliteli zaman geçirmek vb. amaçlarla, sanal ortamlarda veya gerçek ortamlarla sanal uygulamaların birleştirildiği platformlarda, bilgisayarlar, akıllı cep telefonları, VR-BOX 3D gözlükler, oyun konsolları, joystickler vb. teknolojik araçlarla yapılan spor yapma, yarışma, seyahat etme veya gezi, kitap okuma, oyun oynama, sanatsal etkinlikler, vb. aktiviteler dijital rekreasyon kapsamında değerlendirilebilir. En yaygın olarak bilinen dijital rekreatif faaliyetlere bakıldığında, sanal müze gezileri ve sanal turların olduğu görülmektedir. Bu faaliyetlerin dışında gezilip görülmek istenen mağara, şelale, kanyon, dağ gibi doğal güzelliklerin, antik kent, kale, kule, kilise, cami vb., gibi kültürel mekânların sanal gezileri de gerçekleştirilmektedir. Sanal turların yanı sıra bisiklete binmek, yürümek, kuş gözlemciliği yapmak, boks, fitness gibi birçok dijital rekreatif faaliyet de sanal bir şekilde ama gerçeklik hissiyle yapilabilmektedir.

Özetle, gelişen teknoloji hem çalışma hem de günlük hayatta birçok değişime yol açmıştır. Söz konusu değişimler turizm ve rekreasyon alanında da yaşanmaktadır. Bu değişimlerden bazıları insanların tatil sürecinde (tatil tercihi ve karar verme süreci dâhil) faydalandığı teknolojik imkânlar ve rekreatif faaliyetlere katılım şekilleridir. İnsanlar önceden tatil satın alma karar sürecinde, bilgi edinmek için seyahat acentelerinden veya otellerin internet sayfalarından yararlanırken, bugün başta otel odaları olmak üzere işletmelerin diğer birimlerinin $360^{\circ}$ 
panoramik görüntülerini içeren uygulamalar sayesinde, otel işletmesini detaylı olarak inceleyebilmektedirler.

Rekreasyonel aktivitelerde yaşanan teknolojik değişimler ise, fiziksel alanlarda gerçekleştirilen birçok rekreatif faaliyetin, sanal ortamlarda veya fiziksel ile sanalın iç içe geçtiği ortamlarda gerçekleştirilmesi şeklinde açıklanabilir. Golf sporunun sanal gerçeklik ekipmanları ile tamamen sanal bir şekilde gerçekleştirilmesi veya artırılmış gerçeklik teknolojisi desteği ile bir bisiklet yarışı esnasında diğer yarışçıların hızının ve nabzının görülebilmesi örnek olarak gösterilebilir.

\section{YÖNTEM}

Bu çalışmanın amacı, dijital rekreasyon kavramının kapsamını belirlemek ve dijital rekreasyon faaliyetlerini sınıflandırmaktır. Bu amaç doğrultusunda, çalışmada, literatür tarama yöntemi ve ikincil veri kaynaklarından yararlanılmıştır. Çalışma kapsamında ilgili literatür taranarak, teknoloji şirketleri olan Oculupus, HTC, Microsoft Google Earth, Apple vb. birçok firmanın uygulamaları, web sayfaları, forum siteleri ve blogları incelenmiştir. Bu incelemelerle elde edilen dijital rekreasyon faaliyetlerinin uygulamaları, dijital rekreasyon kavramının kapsamını belirlemek amacıyla sınıflandırmaya tabi tutulmuştur. Yapılan sınıflandırma neticesinde, dijital rekreasyon kavramı "Sanal Gerçeklik Tabanlı Dijital Rekreasyon" ve "Artırılmış Gerçeklik Tabanlı Dijital Rekreasyon" olmak üzere iki ana başlığa ayrılmıştır. "Sanal Gerçeklik Tabanlı Dijital Rekreasyon" teması altında "dijital kültürel faaliyetler", "dijital sanatsal faaliyetler", "dijital doğa tabanlı faaliyetler", “dijital sportif faaliyetler", "dijital eğlence faaliyetleri” ve "dijital diğer faaliyetler" olarak 6 kategori yer almaktadır. "Artırılmış Gerçeklik Tabanlı Dijital Rekreasyon" teması altında, "dijital kültürel faaliyetler", "dijital sanatsal faaliyetler", "dijital doğa tabanlı faaliyetler" ve "dijital eğlence faaliyetleri" olarak 4 kategori yer almaktadır. Çalışmada, "Sanal Gerçeklik ve Artırılmış Gerçeklik Uygulamalarının Rekreatif Faaliyetlere Yansıması: Dijital Rekreasyon" kavramını incelemek amacıyla dijital rekreatif faaliyetlerin analiz edilmesine yönelik aşăğıdaki araştırma sorularına cevap aranmıştır.

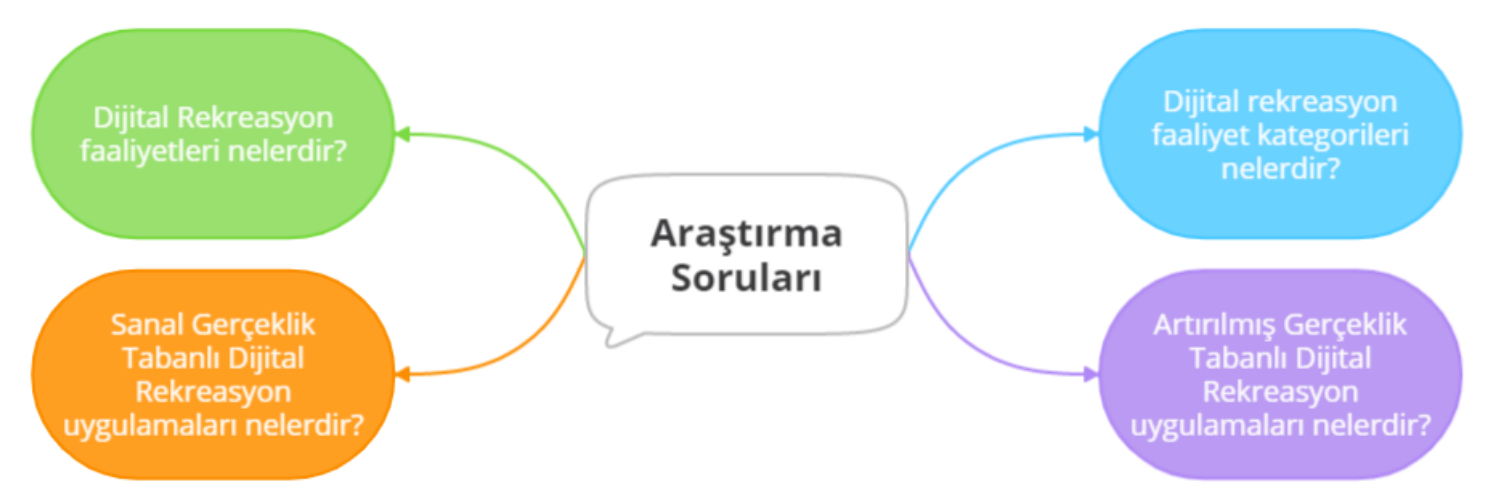

\section{BULGULAR}

Çalışmada, "sanal gerçeklik tabanlı dijital rekreasyon" ve "artırılmış gerçeklik tabanlı dijital rekreasyon" olmak üzere iki tema oluşturulmuştur. Bu temaların altında bulunan, alt kategoriler ve uygulama örnekleri aşağıda verilmiştir. 
Şekil 1: Dijital Rekreasyonun Sınıflandırılması

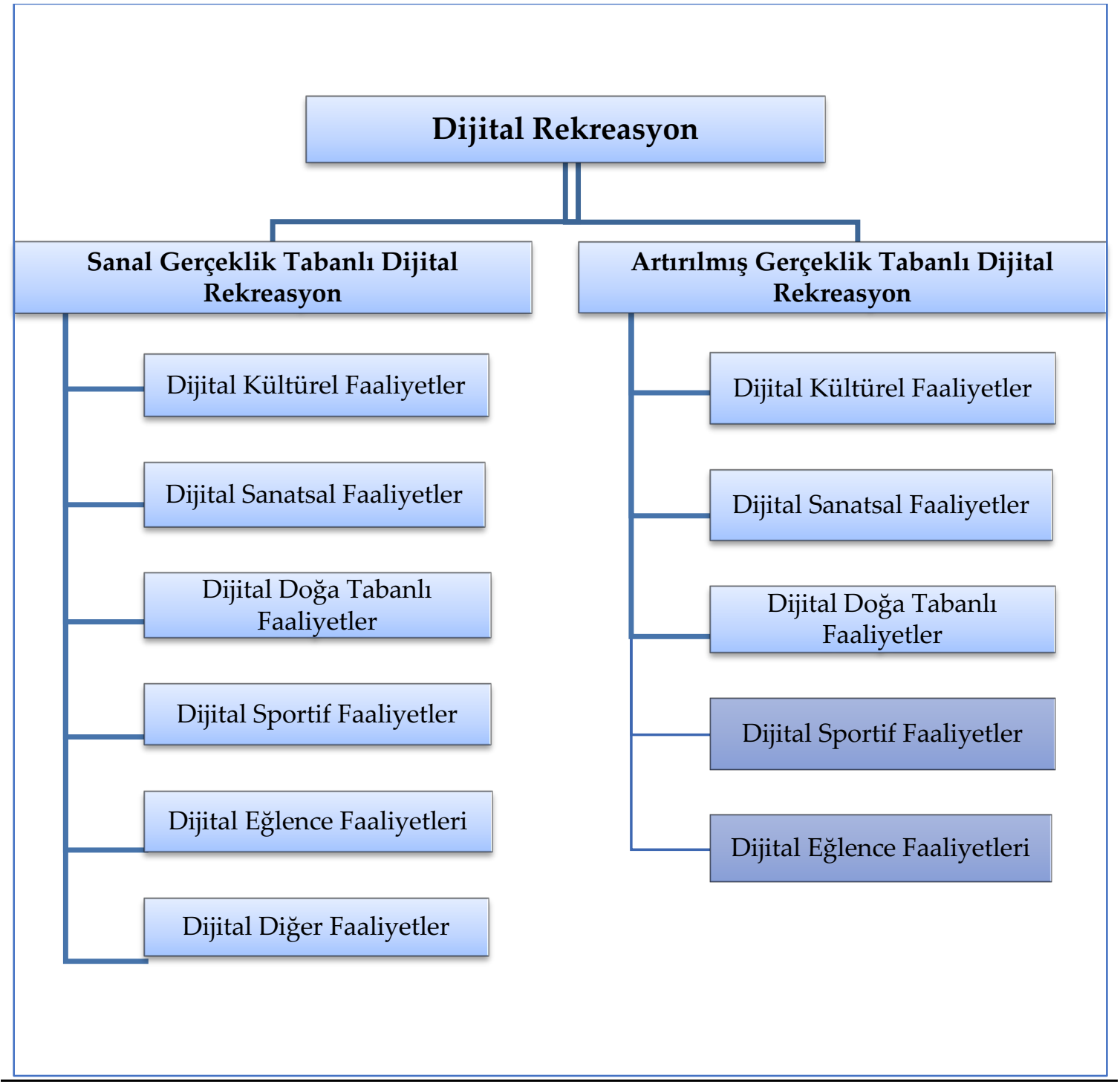

Kaynak: Yazarlar tarafindan derlenmiştir.

\section{Sanal Gerçeklik Tabanlı Dijital Rekreasyon}

Yapılan araştırma sonucunda, sanal gerçeklik tabanlı dijital rekreasyon faaliyetlerinin; dijital kültürel faaliyetler, dijital sanatsal faaliyetler, dijital doğa tabanlı faaliyetler, dijital sportif faaliyetler, dijital eğlence faaliyetleri ve dijital diğer faaliyetlerinden oluştuğu tespit edilmiştir. Aşağıda bu faaliyetlerin neleri içerdiği ve uygulama örnekleri gösterilmiştir. 


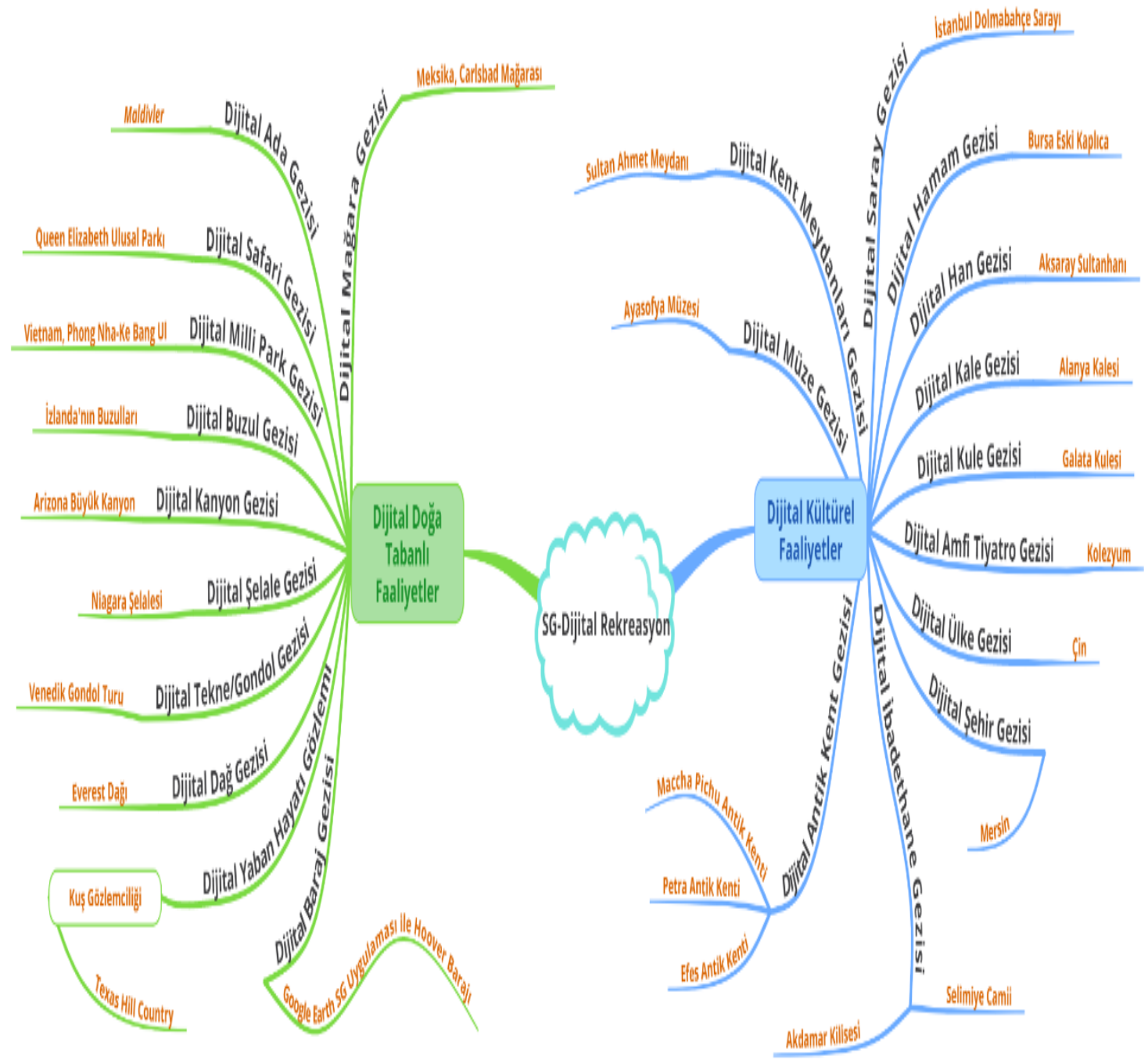

Şekil 2: Sanal Gerçeklik Temelli Dijital Doğa Tabanlı ve Dijital Kültürel Faaliyetlerin Sinıflandırılması ve Uygulamaları

Şekil 2'de görüldüğü üzere dijital doğa tabanlı faaliyetler; dağ, kanyon, mağara, milli park, baraj, şelale, ada, buzul, tekne gezileri ve yaban hayatı gözlem, safari olmak üzere 11 alt başlıkta sınıflandırılmıştır. Bu faaliyetler, $360^{\circ}$ dijital tur şeklinde gerçekleşmektedir. Dijital kültürel faaliyetler ise, antik kent, müze, saray, han, hamam, kale, kule, meydanlar, amfi tiyatro ve dini mekânlar (cami, kilise) ile ülke ve şehir gezileri olmak üzere 12 alt başlıkta sınıflandırılmaktadır. Bu faaliyetlerin, birçoğu 360 dijital tur şeklinde yapılırken, Çin'e yapılan ülke gezisi, Tokyo'daki First Airlines isimli tur firması tarafından sanal gözlük kullanımı ile gerçekleşmektedir. 


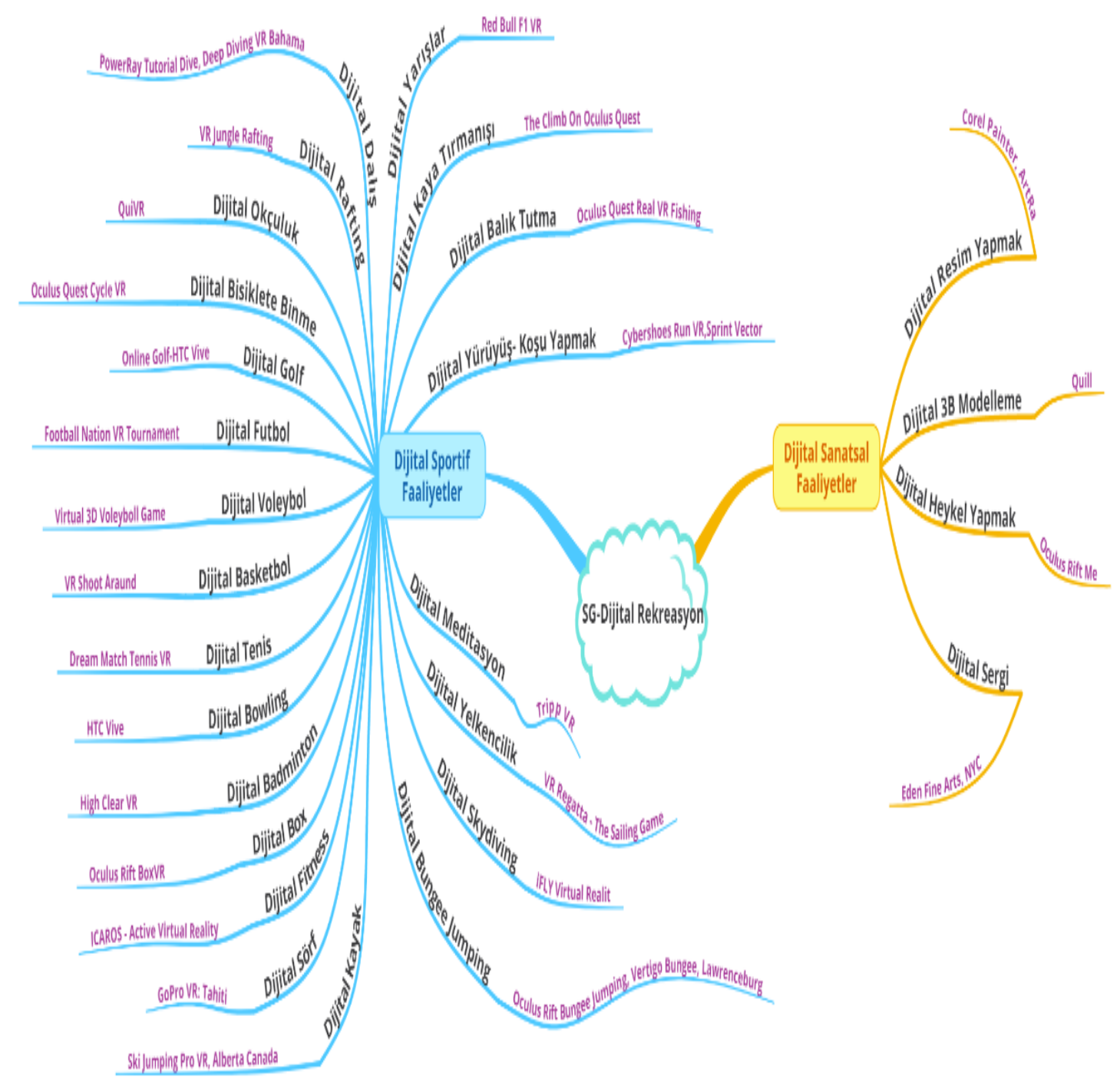

Şekil 3: Sanal Gerçeklik Tabanlı Dijital Sportif ve Dijital Sanatsal Faaliyetlerin Sınıflandırılması ve Uygulamaları

Şekil 3'te görüldüğ̈̈ üzere, dijital sportif faaliyetler: yürüyüş-koşu, bisiklet sürme, kaya tırmanışı, rafting, kayak, bungee jumping, dalış, yüzme, yelkencilik, sörf yapma, badminton, okçuluk, bowling, futbol, voleybol, basketbol, tenis, golf, balık tutma, skydiving, boks, fitness ve meditasyon olmak üzere 23 alt başlık ile sınıflandırılmıştır. Bu faaliyetler, sanal gerçeklik gözlükleri, touch controller cihazları, sensörler ve avuç içi ekranlar aracılığıyla yapılmaktadır. Dijital sanatsal faaliyetler: 3B modelleme, heykel tasarımı, resim yapmak ve sergi olmak üzere 4 alt başlık ile sınıflandırılmıştır. Burada, sergi faaliyeti $360^{\circ}$ dijital gezi şeklinde gerçekleştirilirken, diğerleri sanal gerçeklik cihazları ile gerçekleştirilmektedir. 


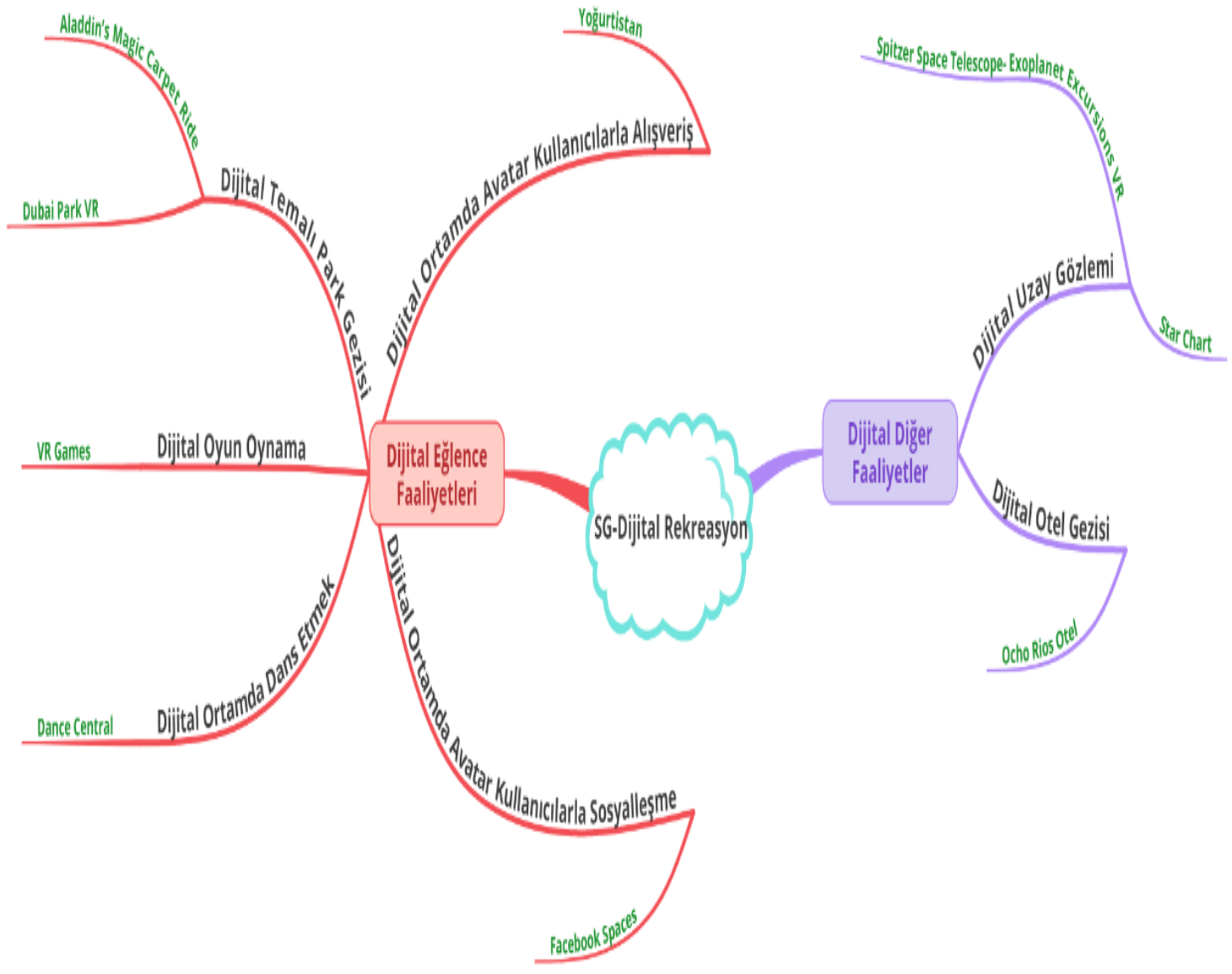

Şekil 4: Sanal Gerçeklik Tabanlı Dijital Eğlence ve Dijital Diğer Faaliyetlerin Sınıflandırılması ve Uygulamaları

Şekil 4'te görüldüğü üzere dijital eğlence faaliyetleri: alışveriş, temalı park gezisi, oyun oynama, dans etme ve sosyalleşme olmak üzere 5 başlık altında sınıflandırılmıştır. Temalı park gezme, alışveriş yapma, sosyalleşme faaliyetleri avatar kullanıcıları ile gerçekleşmektedir. Avatar kullanıcılar, adeta aynı mekândaymış gibi bir araya gelip iletişim kurabilme imkânı veren, etkileşimli bir sanal ortamda buluşmaktadır. Dans etme faaliyeti, sanal gerçeklik cihazlarıyla gerçekleştirilirken, oyunlar hem avatar kullanıcılar aracılı̆̆ıyla hem de sanal gerçeklik cihazlarıyla gerçekleşmektedir. Dijital diğer faaliyetler ise, uzay gözlem ve otel gezisi olmak üzere 2 başlık altında toplanmaktadır. Otel gezisi 360 dijital gezi şeklinde gerçekleştirilirken, uzay gözlem sanal gerçeklik cihazlarıyla gerçekleşmektedir.

\section{Artırılmış Gerçeklik Tabanlı Dijital Rekreasyon}

Yapılan araştırma sonucunda, artırılmış gerçeklik tabanlı dijital rekreasyon faaliyetlerinin; dijital kültürel faaliyetler, dijital sanatsal faaliyetler, dijital doğa tabanlı faaliyetler ve dijital eğlence faaliyetlerinden oluştuğu tespit edilmiştir. Aşağıda bu faaliyetlerin neleri içerdiği ve uygulama örnekleri gösterilmiştir. 


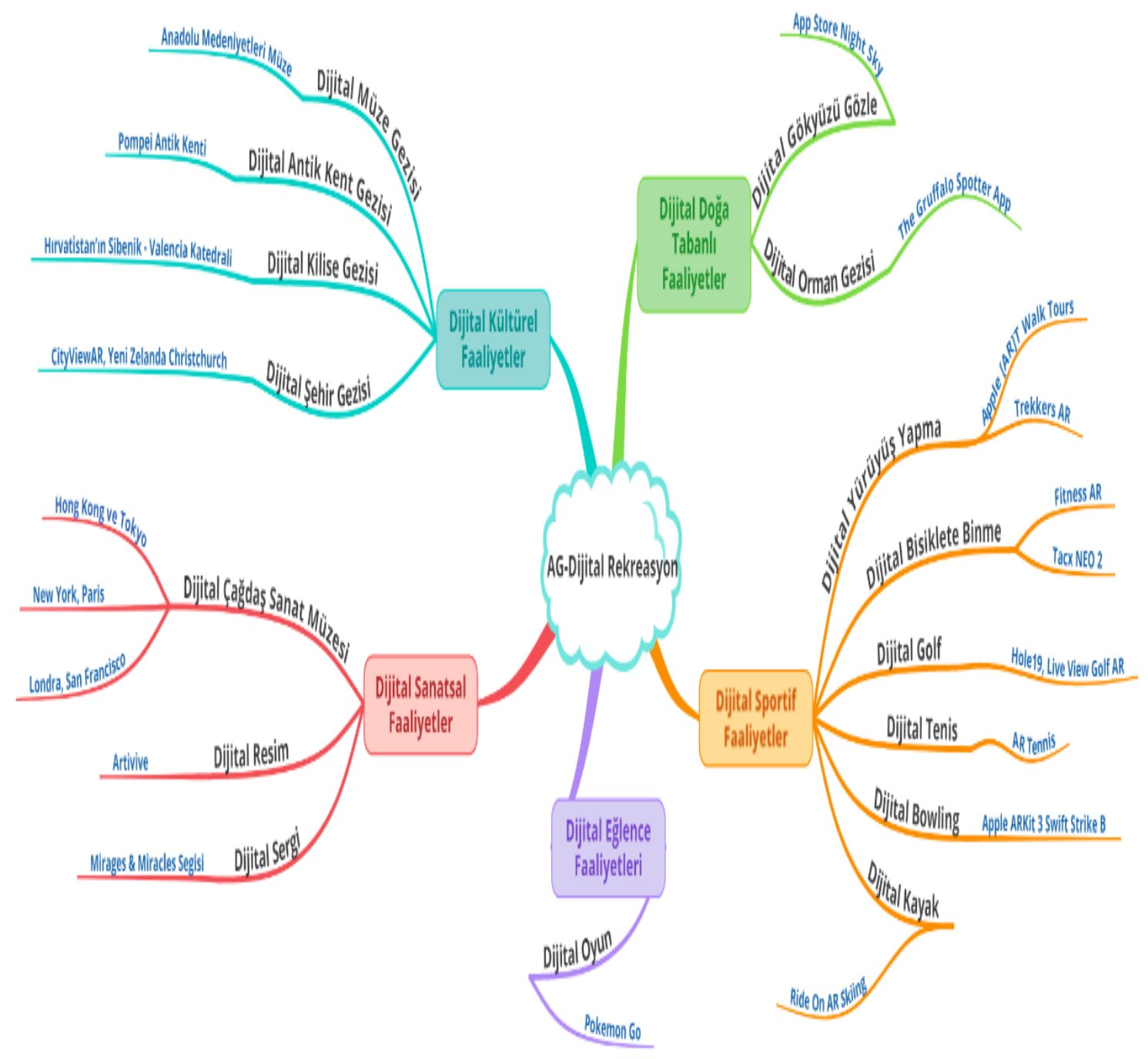

Şekil 5: Artırılmış Gerçeklik Tabanlı Dijital Rekreasyon Faaliyetlerinin Sınıflandırılması ve Uygulamaları

Şekil 5'te görüldüğü gibi dijital kültürel faaliyetler: müze, antik kent, kilise ve şehir gezisi olmak üzere 4 başlık altında, dijital sanatsal faaliyetler: çağdaş sanat müzesi, resim ve sergi olmak üzere 3 başlık altında sınıflandırılmıştır. Dijital doğa tabanlı faaliyetler: gökyüzü gözlem ve orman gezisi olmak üzere 3 başlık altında, dijital sportif faaliyetler: yürüyüş, bisiklete binme, golf, tenis, bowling ve kayak yapma olmak üzere 6 başlık altında toplanmıştır. Dijital eğlence faaliyeti ise, dijital oyun alt başlığından oluşmaktadır. Artırılmış gerçeklik tabanlı dijital rekreasyon faaliyetleri gerçek ile sanal dünyayı bir araya getiren sanal gerçeklik cihazları aracılığıyla gerçekleşmektedir.

$\mathrm{Bu}$ çalışma, gelişen teknoloji sayesinde birçok rekreatif faaliyetin hem sanal ortamda hem de artırılmış gerçeklik teknoloji destekli fiziksel ortamlarda gerçekleştirilebildiğini ortaya koymaktadır. Elde edilen veriler ışığında, dijital rekreatif faaliyetler; doğa tabanlı, kültürel, sanatsal, sportif, eğlence ve diğer aktiviteler olarak tespit edilmiştir. Sanal ve artırılmış gerçeklik tabanlı dijital rekreasyon faaliyetlerinin özellikle spor alanında yoğun olarak kullanıldığı görülmektedir. 


\section{SONUÇ ve ÖNERILER}

Bilgi ve iletişim teknolojilerindeki gelişme askeri sanayiden sağllğa, mimariden eğitime, bankacılıktan üretim endüstrisine ve ulaşıma kadar, insan yaşamının birçok yerinde kendini göstermiş ve insanoğlunun yaşam tarzı ve standartlarında önemli değişimlere neden olmuştur. Teknolojide meydana gelen bu gelişmeler birçok alanda olduğu gibi turizm ve rekreasyon sektörlerinde de kendine yer bulmuştur. Günümüzde sanal gerçeklik ve artırılmış gerçeklik teknolojileri sayesinde, artık insanlar evlerinden çıkmadan da dünyanın diğer ucundaki bir müzeyi, antik kenti veya popüler bir kent meydanını sanal olarak gezebilmektedirler ya da adrenalini yüksek, kaza ve yaralanma riski fazla olan kaya tırmanışı, kanyoning (kanyon geçişi), bungee jumping gibi macera sporlarını yaralanmadan dijital bir ortamda yapabilmektedirler. Bunun yanı sıra, çıktıkları bir doğa yürüyüşünde, kullanılan artırılmış gerçeklik araçları sayesinde yürüyüş aktivitelerini daha ilginç ve zevkli hale getirebilmektedirler.

Söz konusu teknolojilerin sunduğu hizmetlerin önemi, 2019 yılının sonu 2020 yılının başlarında tüm dünyada yayılan COVID-19 pandemisi nedeniyle daha çok anlaşılmıştır. Salgın nedeniyle Türkiye de dâhil olmak üzere, hastalığın bulaştığı ülkelerdeki birçok şehirde ilan edilen sokağa çıkma yasakları sebebiyle insanlar mecburen evlerinde vakit geçirmek zorunda kalmışlar ve bu zamanlarda birçok insan sahip olduğu bilgisayar, akıllı telefon, sanal ve artırılmış gerçeklik cihazları sayesinde dijital olarak rekreatif faaliyetlerde bulunabilmişlerdir.

Buradan yola çıkarak bu araştırmada, dijital rekreasyon kavramının tanımı, kapsamı ve dijital rekreasyon türleri ele alınmış ve belirlenmeye çalışılmıştır. Literatür taraması ve ikincil veri kaynaklarından (bilgi ve iletişim teknoloji şirketlerinin internet sayfaları, bloglar, forum siteleri, sosyal medya) elde edilen veriler incelenmiş, dijital rekreasyon için bir tanım geliştirilmiş, veriler tasnif edilerek dijital rekreasyon, sanal gerçeklik tabanlı ve artırılış gerçeklik tabanlı dijital rekreasyon olarak iki alt başlığa ayrılmıştır. Sanal gerçeklik tabanlı dijital rekreasyon; dijital kültürel - sanatsal - doğa tabanlı- sportif - eğlence - diğer rekreatif faaliyetler olmak üzere altı başlık altında sınıflandırılmıştır. Artırılmış gerçeklik tabanlı dijital rekreasyon ise; kültürel sanatsal- doğa tabanlı- sportif- eğlence faaliyetleri olmak üzere beş başlık altında kategorize edilmiştir. Ayrıca sınıflandırılan her başlık için örnek dijital rekreasyon uygulaması, etkinliği verilmiştir. Yapılan incelemelerde en çok karşılaşılan dijital rekreasyon etkinliklerinin, sanal gerçeklik tabanlı dijital sportif faaliyetler (dijital golf, futbol, tenis, voleybol, yürüyüş-koşu vb. etkinlikler), dijital kültürel faaliyetlerin (antik kent, müze, saray, han, hamam, kale, meydanlar, dini mekânlar (cami, kilise) gezileri vb. etkinlikler) ile dijital doğa temelli aktiviteler (dijital dağ, kanyon, mağara, milli park, şelale, ada gezileri vb. etkinlikler) olduğu görülmektedir. Artırılmış gerçeklik tabanlı dijital rekreasyon etkinliklerine bakıldığında ise, en popüler olanların dijital sportif faaliyetler (dijital yürüyüş, bisiklete binme, bowling, tenis vb. aktiviteler) ile dijital kültürel faaliyetlerin (dijital müze, antik kent, şehir gezileri) olduğu görülmektedir.

Bu sonuçlardan yola çıarak, şu önerilerde bulunulabilinir,

- Kültür ve Turizm Bakanlığı ile Milli Saraylar İdaresi Başkanlığı'na bağlı tüm müze ve sarayların ücretli veya ücretsiz olarak dijital gezilere açılması sağlanarak, ülke tanıtımına katk1da bulunulabilinir.

- Günümüzde dijital gezilerin yoğun olarak müzelere yönelik yapıldığı görülmektedir. Müzelerin yanı sıra antik kentler, kaleler, milli parklar, doğal koruma alanları vb. turistik çekiciliğe sahip yerlere yönelik de sanal geziler düzenlenebilir.

- Aynı zamanda söz konusu alanlarda artırılmış gerçeklik teknoloji ile deneyimler ilginç deneyimler ortaya çıkarılabilir. Örneğin Topkapı Sarayı Divan Salonu gezilirken, artırılmış 
gerçeklik gözlükleriyle bakıldığında, divana başkanlık eden sadrazam ile ayakta bekleyen vezirler ve paşaların bulunduğu Divan- 1 Hümayun görüntülenebilir. Bu tip uygulamalar diğer müzelerde de uygulanabilir.

- Gelecekte bu konuyla ilgili yapılacak araştırmalar için spesifik olarak Türkiye ölçeğinde uygulanmakta olan dijital rekreasyon faaliyetleri incelenebilir.

\section{KAYNAKÇA}

Altınpulluk, H., ve Kesim, M. (2015). Geçmişten Günümüze Artırılmış Gerçeklik Uygulamalarında Gerçekleşen Paradigma Değişimleri. XVII. Akademik Bilişim Konferansı - AB 2015, 4-6 Şubat 2015, Eskişehir, Türkiye.

Arat, T. ve Baltacıoğlu, S. (2016). Sanal Gerçeklik ve Turizm. Selçuk Üniversitesi Sosyal Bilimler Meslek Yüksek Okulu Dergisi, 19 (1): 103-118.

Azuma, R.T. (1997). A Survey of Augmented Reality. Presence: Teleoperators and Virtual Environments, 6 (4): 355-385.

Bahar, M., Yüzbaşıŏlu, N. Topsakal ve Y. (2019). Akıllı Turizm ve Süper Akıllı Turist Kavramları Işığında Geleceğin Turizm Rehberliğine Bakış. Journal of Travel and Tourism Research, 14: $72-93$

Bingöl, B. (2018). Yeni Bir Yaşam Biçimi: Artırılmış Gerçeklik (AG). ETKÍLEŞIM: Üsküdar Üniversitesi İletişim Fakültesi Akademik Dergisi, 1 (1): 44-55.

Bryce, J. (2001). The Tecnological Transformation of Leisure. Social Science Computer Review, 19(1): 7-6.

Cankül, D., Doğan, A. ve Sönmez, B. (2018). Yiyecek-İçecek İşletmelerinde İnovasyon ve Artırılmış Gerçeklik Uygulamaları, İşletme Araştırmaları Dergisi, 10(3): 576-591.

Caudell, T. P., and Mizell, D. W. (1992). Augmented Reality: An Application of Heads-Up Display Technology to Manual Manufacturing Processes. Twenty-Fifth Hawaii International Conference on System Sciences, 7-10 January 1992, Kauai HI, USA.

Cover, S. A., Ezquerra, N. F., O'Brien, J. F., Rowe, R., Gadacz, T., and Palm, E. (1993). Interactively Deformable Models for Surgery Simulation. IEEE Computer Graphics and Applications, 13(6): 68-75.

Demirezen, B. (2019). Artırılmış Gerçeklik ve Sanal Gerçeklik Teknolojisinin Turizm Sektöründe Kullanılabilirliği Üzerine Bir Literatür Taraması, Uluslararası Global Turizm Araştırmaları Dergisi, 3 (1): $1-26$.

Ekinci, E. ve Özer, U. (2019). Bir Serbest Zaman Etkinliği Olarak Sanal Gerçeklik, 2. Uluslararası Rekreasyon ve Spor Yönetimi Kongresi 11 - 14 Nisan, Bodrum, Türkiye.

Guttentag, D. A. (2010). Virtual Reality: Applications and Implications for Tourism, Tourism Management, 31: 637-651.

Hjalager, A., M. (2015). 100 Innovations that Transformed Tourism, Journal of Travel Research, 54 (1): 3-21.

İçten, T. ve Bal, G. (2017). Artırılmış Gerçeklik Üzerine Son Gelişmelerin ve Uygulamaların İncelenmesi. Gazi Üniversitesi Fen Bilimleri Dergisi, 5(2): 111-136 
Kaleci, D., Tepe. ve Tüzün H. (2017). Üç Boyutlu Sanal Gerçeklik Ortamlarındaki Deneyimlere İlişkin Kullanıcı Görüşleri, Türkiye Sosyal Araştırmalar Dergisi, 21 (3): 669-689.

Kamacıoğlu, B. (2018). İnteraktif Bir Alan Olan Artırılmış Gerçeklik Teknolojisi ve Uygulama Örneği. Yayınlanmamış Yüksek Lisans Tezi. Yıldız Teknik Üniversitesi, İstanbul.

Kozak, A. M. ve Özkeroğlu, Ö. (2018). Turizm ve Rekreasyon Kavramları: Sanal Bakış ile Değerlendirme. II. Uluslararası Sürdürülebilir Turizm Kongresi, 20-22 September 2018, Gümüşhane, Türkiye.

Hobson P. J. S. and Williams, P. P. (1997). Virtual Reality: The Future of Leisure and Tourism ? World Leisure E Recreation, 39 (3): 34-40.

Mokhtarian, P.L., Salomon, I. ve Handy, S.L. (2006). The Impacts of ICT on Leisure Activities and Travel: A Conceptual Exploration. Transportation, 33 (3): 263-289

Öngider, M., U. ve Yazıcı, S. (2020). $360^{\circ}$ Sanal Gerçeklik Videolarının Turistlerin Seyahat Motivasyonuna Etkisi Üzerine Deneysel Bir Araştırma, Türk Turizm Araştırmaları Dergisi, 4(1): 121-136.

Özgüneş, R., E. ve Bozak, D. (2017). Turizm Sektörünün Sanal Rakibi (Mi?): Arttırılmış Gerçeklik, Uluslararası Türk Dünyası Turizm Araştırmaları Dergisi, 2 (2): 146-160.

Somyürek, S. (2014). Öğrenme Sürecinde Z Kuşağının Dikkatini Çekme: Artırılmış Gerçeklik. Eğitim Teknolojisi Kuram ve Uygulama, 4(1): 63-80.

TDK. (2020). https://sozluk.gov.tr/ [Erişim Tarihi: 10.03.2020].

Yılmazel, Ö. (2013). Temel Bilgi Teknolojileri II, Anadolu Üniversitesi Yayınları, Eskişehir.

Yolcu, T., Gökdemir Ekici, S., Sütütemiz, N., ve Altunışık, R. (2017). Sanal Gerçeklik (Virtual Reality) Gözlüklerinin Teknolojilerinin Deneyimsel Pazarlama Bağlamında Kullanımına Yönelik Keşifsel Bir Araştırma, 6th International Conference Of Strategic Research On Social Science and Education. 12-14 May 2017, Prague / Czech Republic. 